\title{
Data Enriched Voice Service Analysis and Forecast
}

\author{
Qiaohong Zhou \\ School of Economics and Management, South West Jiaotong University \\ Jiu Li Ti Campus, Juan Cheng Zhai 13-107 \\ Chengdu 610031, China \\ E-mail: qiaohong.zhou@gmail.com \\ Guohua Zhou \\ School of Economics and Management, South West Jiaotong University \\ Tel: 86-28-8763-4066Ｅ-mail: ghzhou@126.com
}

\begin{abstract}
In this article, we compare the traditional call model and the new call model where voice and data are united together in a globally interoperable way, and analyze the data enriched voice service via call personalization, call-to-browse, and call-to-advertise. This work aims to better understand the characteristics and current situations of voice service in the telemarketing industry and forecast its market potential.
\end{abstract}

Keywords: Voice service, Data personalization, Call- to -browse, Advertisement

\section{Introduction}

3GSM World Congress 2007 in Barcelona has marked a turning point in the availability, or at least announcement of, multimedia enhancements to Caller ID and Call Alerts. As would be expected for such a new area, there are many ideas about how to proceed. Some offers are positioned as extensions to "ringtone", while others have a broader vision of how rich media can be added to the telephone call. Some service requires either calling parties to be on each other buddy lists; or both calling parties to install client software, while others do not. Some platforms are SIP/IMS/VoIP oriented, while a small number can be implemented in standard $2.5 \mathrm{G}$ and $3 \mathrm{G}$ environments. Some use relatively sophisticated service platforms while others are quite basic point products. Most are launched on the web independent of operators while some only work with operators' network infrastructure. Some claim "patents pending" while others have granted patents, though in quite diverse areas and sometimes rather late.

\section{The Call model}

\subsection{The traditional call model}

The traditional call model (Figure 1) only makes the benefit for the operator by charging a fee during the in-call, there are no commercial activities during pre-call and post-call.

\subsection{The new call model}

The new call model (Figure 2) brings new and diverse commercial activities during the pre-call and post-call periods, which in turn generate new business value.

\section{Call Personalizations}

\subsection{Mobile music service market}

From the table 1,we find that a huge share of mobile music revenue and consumers come from personalized services, among them ringback tone is the largest, full-track download still marginal, ringtone ARPU is decreasing while ring back tone ARPU is still increasing within next 3 years. Other studies from OVUM even foresee a decrease of total revenues from ringtones and wallpaper download in APAC during the same period. While ringtone service revenue is expected to decrease, it leaves room for the growth of new music and personalization services.

\subsection{Innovation in the ring tone personalization area (Figure3)}

Major innovation is happening in the call personalization area, mainly coming from start-up companies highly invested by venture capitals looking for the next ringtone application.

The competitors listed here typically have early Skype implementations or private beta tests: 
$\diamond$ Gizmoz allows to create 3D animated avatars based on user pictures. It raised $\$ 6.5$ million recently from investors, including DoCoMo. It announced a partnership with AOL for talking 3D avatars ${ }^{[1]}$. (Figure4)

$\diamond \quad$ Vringo allows to create a community of users with whom you can share content as a ringtone when you call them. Portfolio of licensed music and video content is available ${ }^{[2]}$. (Figure5)

$\diamond$ Comverse has developed Klonies as a customizable avatar service for mobile and Internet calls. Currently its service is available to Skype users ${ }^{[3]}$. (Figure6)

$\diamond \quad$ Emotive has an application called Ringjam which allows callers to customize Internet call alert with purchasable licensed music and video content. Ringjam is currently available on Skype ${ }^{[4]}$. EMotive has raised $\$ 7.7$ million from investors including Warner Music Group ${ }^{[5]}$. (Figure7)

$\diamond \quad$ Monikker starts as the next Generation of Ringtone and Caller ID, as the caller can choose for each call, multimedia - sound, image and text message, same across fixed, mobile or broadband (VoIP, SIP, IMS...) ${ }^{[6]}$. (Figure8)

$\diamond \quad$ Innovation is also driven by major Internet players aiming to move towards the mobile world through their IM and community pages. Key Internet players are Google, Yahoo, MSN, AOL, Skype, Facebook, etc; while they come to compete with carriers, innovation in personalization servers as a key differentiator.

\section{Call - to - Browse Experience}

While $76 \%$ of mobile users in developed countries have Internet through their mobile phones, only $32 \%$ use the service

[7]. Technology is giving more possibilities, more choice, but also more complexities. Placing or answering a voice call or a SMS is still what most people can or are willing to do. Simplification of the end-user experience is required to bring any enhanced service to the mobile world. Operators have shown reluctance in bringing content to their subscribers. New mobile players are actively exploring this opportunity.

The operator uses the SMS simple interface to request for premium content (weather, stocks, addresses, etc), which is limited in content size (due to SMS) and fastidious in navigation. (Figure9)

The mobile phone camera can be used as a 2D barcode reader. Pictures can be decoded into 400 bytes information such as the contact details or the URL. End users just need to take a picture of a magazine or the billboard instead of typing complex URL address, and do not require to handle printing media. (Figure10)

New devices such as iPhone include direct access buttons on phone menu to embedded online applications such as Maps, Weather, Stocks, etc. Often portal services can create new widgets coming directly on the phone interface (i.e., Facebook). (Figure11)

Yahoo Go! offers a one-stop-shop for mobile client to select from all of Yahoo Internet world: email, news, flick pictures, maps, finance, RSS feeds, etc and a mobile browser that adapts Internet content to mobile screen size. (Figure12)

Keying in a URL or clicking on a hyperlink works conveniently on a PC, but not so on a mobile device. Many attempts have tried to replace the trigger of a data session by a simpler action: SMS, barcode, specific mobile client, or even RFID tags. But attempts resulted in either a limited experience or more complicated end-user experience. Coupling or triggering a data session before or after a voice call could be a more natural way to proceed as every mobile phone owner knows how to place a phone call.

Many start-up targets this function such as one Australian company Monikker which sets up their network market as: Figure13

Value Proposition:

$\diamond \quad$ Consumers can 'make it mine' if they like a call based on Monikker and order the music or image.

$\diamond \quad$ Content owners get a new 'viral' distribution channel - consumers promoting their content at no cost!

$\diamond$ Scenario

$\diamond \quad$ Business pays MSP to deliver a call

$\diamond$ monikkers and receives customer feedback.

$\diamond \quad$ Parties

$\diamond \quad$ Party A chooses a monikker, knowing that it is available to others

$\diamond \quad$ Party B chooses to "make it mine" and pays

$\diamond \quad$ Content provider chooses this distribution option and MSP serves as the intermediary

$\diamond \quad$ Business Model

$\diamond \quad$ MSP earns a share of every sale from unique platforms 
$\diamond$ Has lower advertising and promotion costs than other media. New platform for "Hits"

$\diamond \quad$ Call monikker can be free, but full song paid for - customers become advocate

\section{Call-to- advertise}

\section{1 market view}

The average consumer spends 3 hours daily watching TV, on which advertisers spend \$79 billion yearly, 1 hour using their mobile, on which advertisers spend \$2 billion in 2007.Mobile advertisement global market revenue is $\$ 1.5$ billion in 2006 , i.e., $0.2 \%$ of the $\$ 435$ billion spent for advertisement on any media ${ }^{[8]}$. Mobile advertising revenue is projected to reach $\$ 11.3$ billion in $2010^{[9]}$, $\$ 13.8$ billion in $2011^{[10]}$; In Japan, mobile marketing was as big as $\$ 850$ million already in 2006.

Multimedia and interactive technologies have been adopted on mobile (Multimedia devices, MMs, Mobile TV, 3G, etc), and Mobile operators possess huge data about their subscriber profiles and behaviors, that other media may not have. Among all mobile users, $34 \%$ of them are ready to accept mobile advertisement in exchange of free content ${ }^{[1]}$. All these will make this market grow very fast.

According to a survey from $\mathrm{OPA}^{[7]}, 50 \%$ of mobile users in developed countries use their mobile device the same brand as their computer. Big Internet players represent most of the mobile traffic as well. Google, Yahoo and MSN are introducing key assets on the mobile Internet to take further control. Applications are currently free of charge, free of advertisement. But it can be easily extended to include advertisement, their first source of revenues. (Figure14)

\subsection{Advertisement insertion on mobile}

Mobile advertisement can be improved by using user profile and behavior information, providing the user with advertisement of goods \& services which he likes, when he needs. Mobile Advertisement could reach higher efficiency by associating multimedia advertisement with voice calls and SMS. Voice call is still the first killer application for mobile users. The figure below compares the efficiency of different mobile advertisement options. (Figure 15)

\subsection{Advertising and Sponsored Service (Figure 16)}

\section{Value Proposition}

$\diamond \quad$ Businesses provide branded but interesting monikkers to customers at no charge (Sponsored mode)

$\diamond$ Consumers option in to receive advertisements as call alerts (for calls without monikkers) and post-call advertisement time or location based alerts possible. Can leave material in address book and on time line.

$\diamond$ Scenario

$\diamond \quad$ Business pays Intermediary or MSP - new advertising platform with measurable delivery.

$\diamond$ Parties

$\diamond \quad$ Party B - Consumer receiving calls, may opt in for advertising

$\diamond \quad$ Party A- Gets interesting monikkers at lower price in sponsored mode

$\diamond$ Business Model

$\diamond \quad$ Business pays for the new option to promote brand and leave messages with customers

$\diamond$ Can include "click to call", click to "make it mine"

$\diamond \quad$ Pay for exposure, pay for results

\section{Opportunity \& Revenue forecast}

\subsection{Market potential evaluated in APAC}

Data enriched voice service market, from four streams (advertising, entertainment, information, communication), will grow to $€ 80$ billion in revenue by 2010 in APAC. The figure attached presents revenue forecast for call personalization service in APAC for the period of 2007 through $2010^{[12]}$. (Figure 17)

\subsection{Market potential for China}

TD-SCDMA 3G subscribers China will jump to 28 million by 2011, up from 1.1 million subscribers in 2007, and estimated 6.4 million in 2008. A key revenue driver in China will come from the applications that will be enabled by $3 \mathrm{G}$. Chinese consumers will be able to access the Internet, download music, stream Internet video, use mobile mailboxes, pay bills online and engage in mobile blogging and interactive 3D gaming through their mobile phones. China $3 \mathrm{G}$ value-added services market will grow to $\$ 19.5$ billion in revenue by 2011 , maintaining a Compound Annual Growth Rate (CAGR) of $17.4 \%$ from $\$ 8.8$ billion in $2006^{[13]}$., which shows the grand opportunities for call personalization service in china. 
The figure 18 attached presents revenue forecast for $3 \mathrm{G}$ value-added services in China for the period of 2006 through $2011^{[13]}$.

However, blocking points needs to be addressed to go further in business evaluation such as: low penetration of capable devices on the Chinese Market compared to other countries; difficulty to protect patents in China; lack of local structure and operations in china to provide local support as requested by Chinese operators; maturity of the product for quick commercial launch with required feature (advertisement).

\section{Conclusions and suggestion}

Voice and data united in a globally interoperable enhanced call model, and the customer can use any handset type VoIP, 3G, Smartphone, Softphone, Hardphone and any network as common as CLI (command line interface), are integral to enrich more personal communications.

In the future, VoIP will be a grand threat to the mobile operator for voice service, because the cost of VoIP is much lower. But data enriched voice service is a benefit, as mobile operators can still charge at the same price for voice: valued service provided for a monthly subscription fee plus per call charges for some applications and all of the Internet business models, and keep on being attractive as they offer data services on top of voice.

For such a new area there are many ideas about how to proceed. Some claim "patents pending" while others have granted patents, though in quite diverse areas and sometimes rather late. However potential investors should make their own assessment.

\section{References}

Gizmoz. (Online) Available: http://biz.yahoo.com/prnews/080317/aqm047.html?.v=42 (March 1, 2008).

(Online) Available: http://www.vringo.com/ (January 10,2008).

(Online) Available: http://skype.klonies.com/ ((January 12, 2008).

(Online) Available: http://ringjam.com/ (January 12, 2008).

(Online) Available: http://www.monikker.com/home.php (March 1, 2008).

(Online) Available: http://64.13.250.16/newsletter.php?newsId=52\&newsType = pr((January 20,2008).

Emarket. (September 18, 2006). Mobile Ad Market on a Roll, (Online) Available: http://www.emarketer.com/Article.aspx?id=1004165 (November 25,2007).

(Online) Available: http://www.zenithoptimedia.com/home/ (September 25,2007).

Emarketer. Mobile Advertising Exposure Rising (March 7,2008). (Online) Available: http://www.emarketer.com/SiteSearch.aspx?arg=Mobile+Advertising+Exposure+Rising\&src=search_go_articles (March 20,2008).

Online Publisher Association (March, 2007), Available: http://www.online-publishers.org/media/176_W_opa_going_mobile_report_mar07.pdf (March 12, 2008).

(Online) Available: http://alcatel-lucent.com (March 6, 2008).

Jonathan Cassell. (25/07/2007). Government Drives 3G Wireless Transition in China, (Online) Available: http://www.isuppli.com/news/default.asp?id=8237\&m=7\&y=2007, (March 6, 2008).

RafatAli. (April 2007). Warner Music And Other Invest \$7.7 Million In "Push Ringer" Firm emotive, (online) Availabl: http://www.moconews.net/entry/warner-music-and-other-invest-77-million-in-push-ringer-firm-emotive/ (January 20,2008). 
Table 1. APAC (excl Japan) Mobile Music Service Revenues \& Forecast

\begin{tabular}{|c|c|c|c|c|c|c|c|}
\hline & 2006 & 2007 & 2008 & 2009 & 2010 & 2011 & $\begin{array}{l}2006-2011 \\
\text { CAGR(\%) }\end{array}$ \\
\hline Total mobile subscribers $(M)$ & 782.2 & 966.4 & $1,108,50$ & $1,239.20$ & $1,334.90$ & $1,432.20$ & 12.9 \\
\hline \multicolumn{8}{|l|}{ Ringtone customers } \\
\hline Ringtone customers at year-end $(M)$ & 182.1 & 242.1 & 295.5 & 348.9 & 401.5 & 453.6 & 20 \\
\hline Share of total mobile subscribers $(\%)$ & 20 & 30 & 30 & 30 & 30 & 30 & \\
\hline Ringtone revenue(US\$M) & 927.4 & $1,267.40$ & $1,521.50$ & $1,735.80$ & $1,918.00$ & $2,061.20$ & 17.3 \\
\hline Monthly ARPU(\$) & 0.5 & 0.5 & 0.5 & 0.5 & 0.4 & 0.4 & -4.1 \\
\hline \multicolumn{8}{|l|}{ Ringback tone customers } \\
\hline Ringback tone customers & 244.5 & 347.2 & 416.1 & 476.7 & 533.9 & 598 & 19.6 \\
\hline Share of total mobile subscribers $(\%)$ & 30 & 40 & 40 & 40 & 40 & 40 & \\
\hline Subscription & 477.4 & 889.4 & $1,259.80$ & $1,658.90$ & $2,076.90$ & $2,522.80$ & 39.5 \\
\hline Content & 672.6 & $1,122.80$ & $1,569.70$ & $1,998.20$ & $2,356.10$ & $2,693.20$ & 32 \\
\hline Total & $1,150.00$ & $2,012.10$ & $2,829.40$ & $3,657.00$ & $4,433.00$ & $5,216.00$ & 35.3 \\
\hline Monthly ARPU(\$) & 0.5 & 0.6 & 0.6 & 0.7 & 0.7 & 0.8 & 8.9 \\
\hline \multicolumn{8}{|l|}{ Mobile full-track music customers } \\
\hline $\begin{array}{l}\text { Total Mobile full-track music } \\
\text { customers }(M)\end{array}$ & 2.8 & 7.9 & 14.8 & 24.9 & 39.5 & 55.7 & 82 \\
\hline Share of total mobile subscribers $(\%)$ & 0 & 0 & 0 & 0 & 0 & 0 & \\
\hline Total revenue & 44.9 & 156.6 & 391.1 & 776.3 & $1,468.90$ & $2,466.20$ & 122.8 \\
\hline Monthly ARPU(\$) & 1.34 & 1.65 & 2.20 & 2.60 & 3.10 & 3.69 & \\
\hline
\end{tabular}

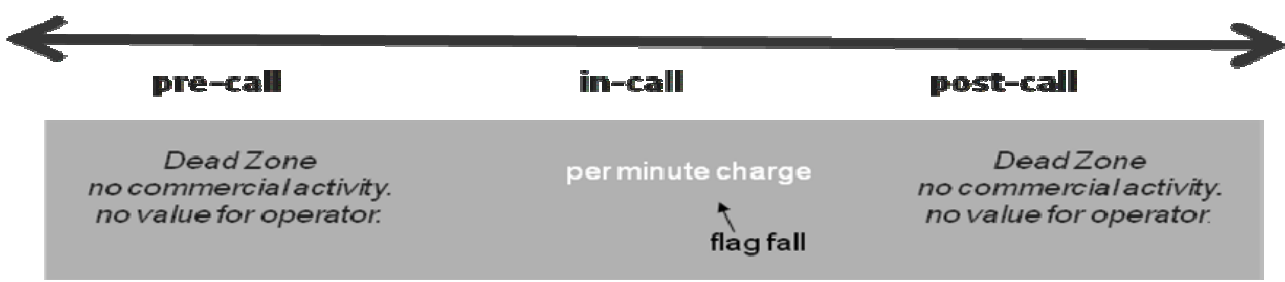

Figure 1. Traditional call model

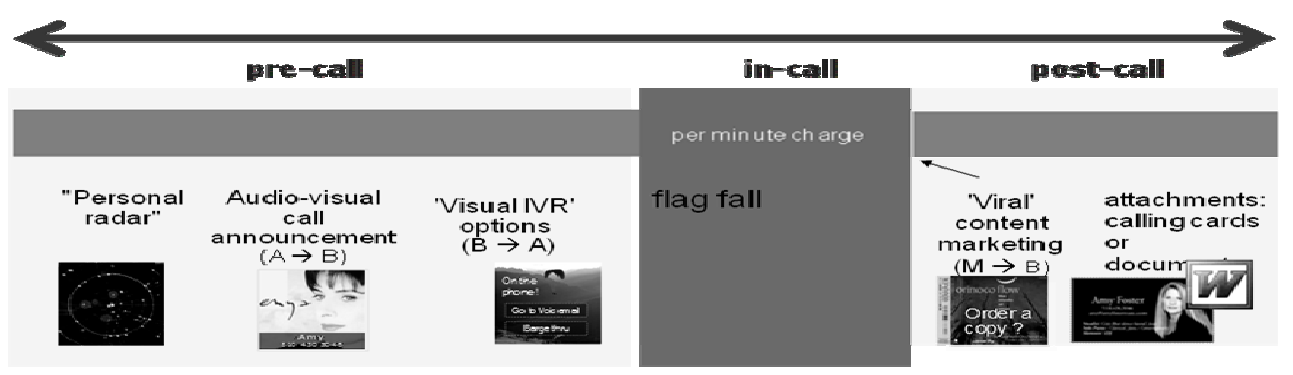

Figure 2. New call model

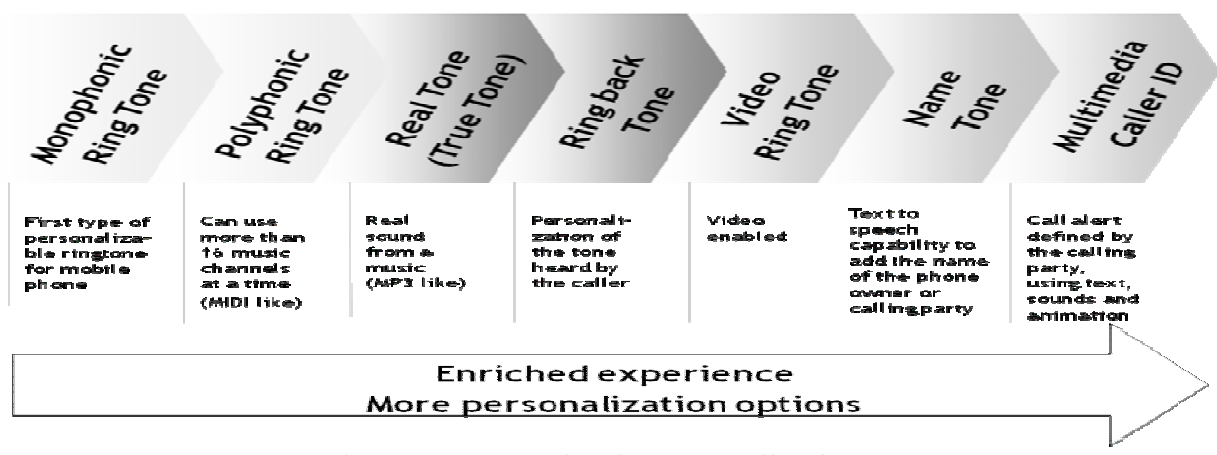

Figure 3. Innovation in personalization 

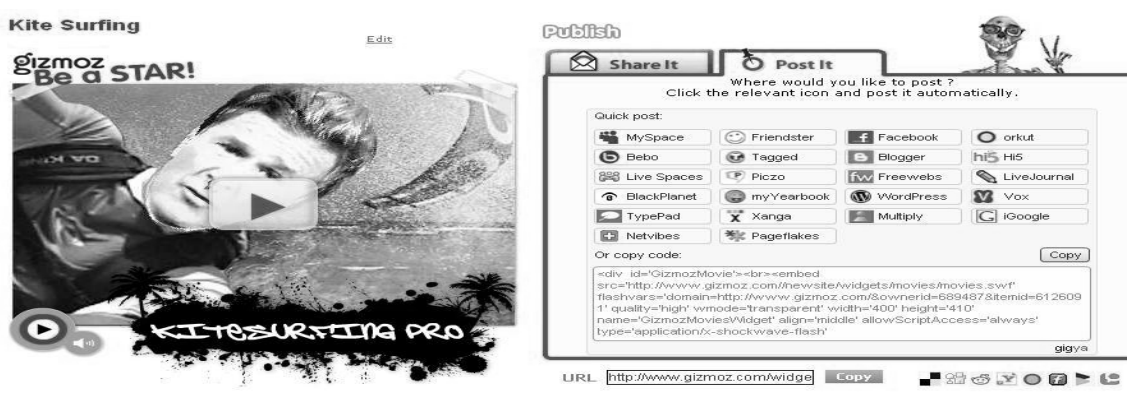

Figure 4. Gizmoz application

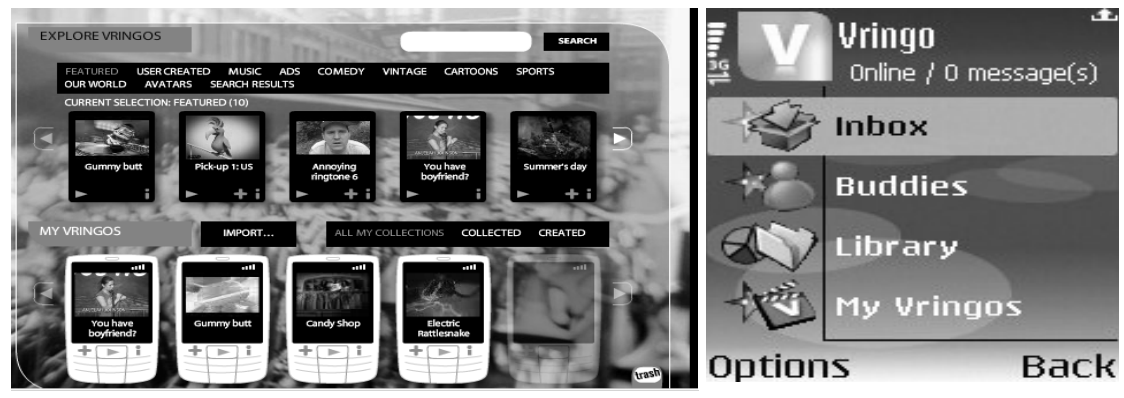

Figure 5. Vringo application

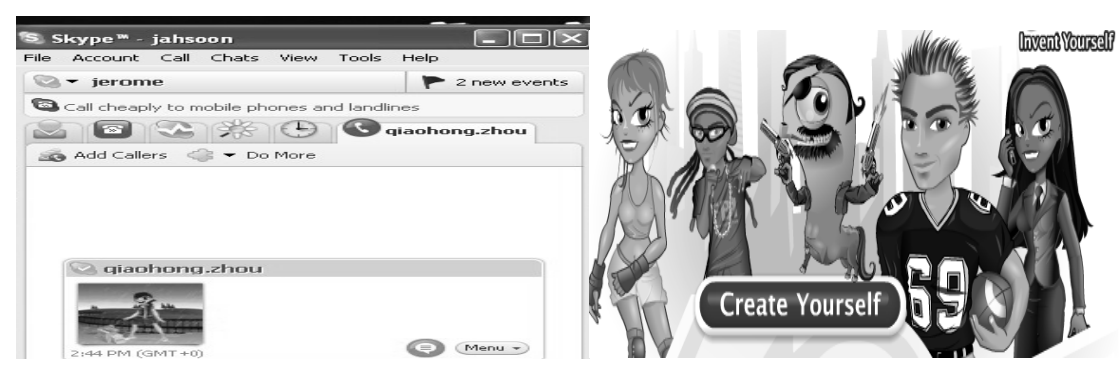

Figure 6. Klonies application

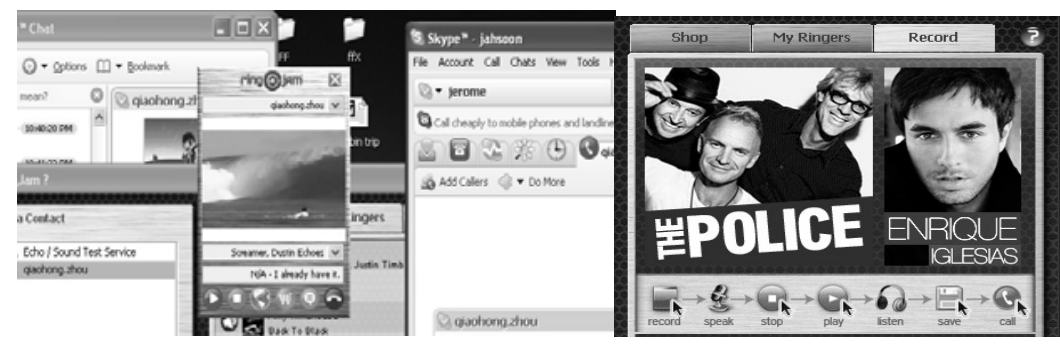

Figure 7. Ringjam application
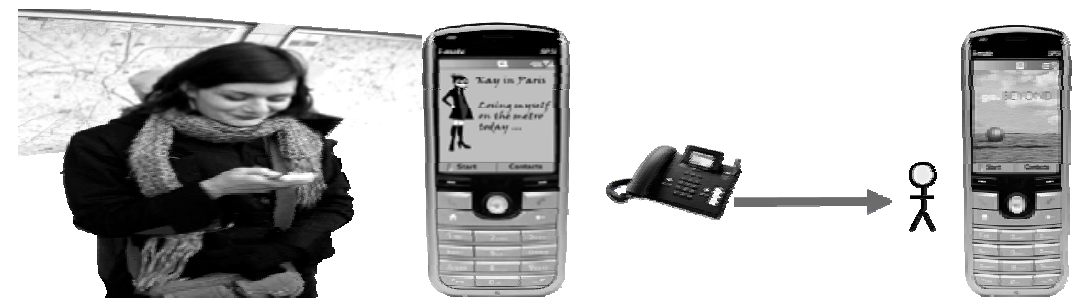

Figure 8. Monikker application 


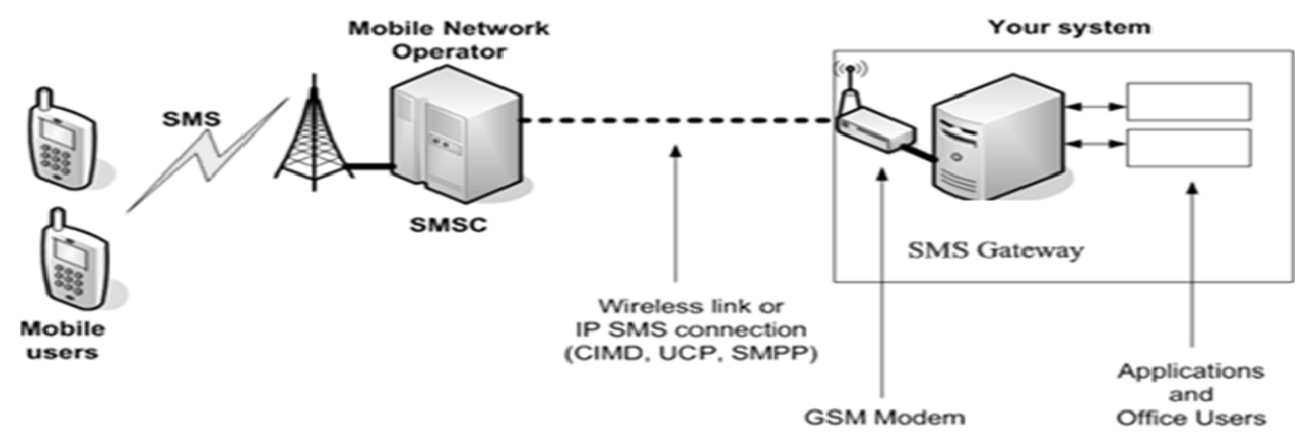

Figure 9. SMS portal

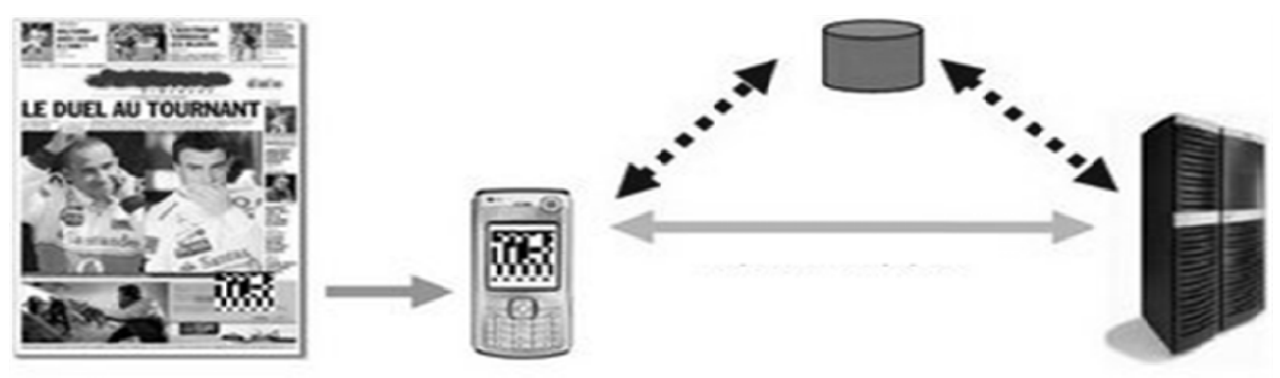

Figure 10. 2D bar code

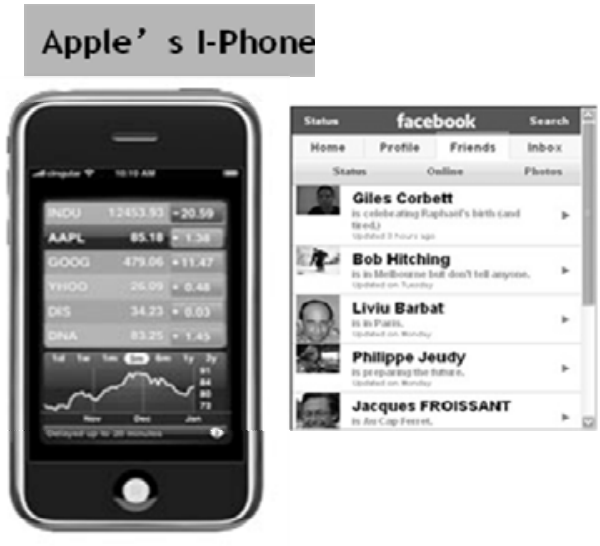

Figure 11. Apple's I-Phone

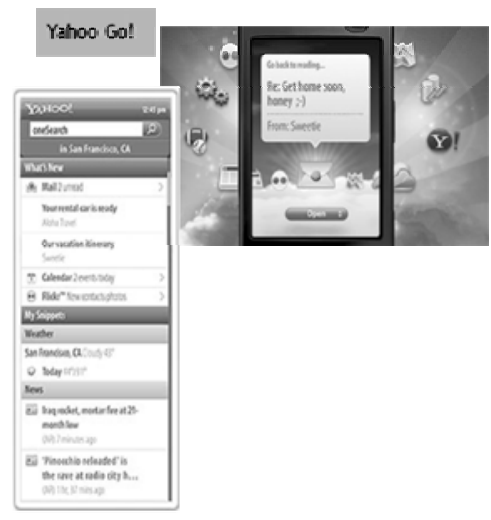

Figure 12. Yahoo Go

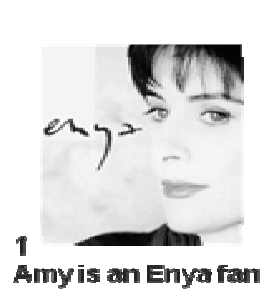
-..

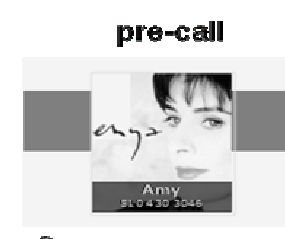

2

mo hercalls are announced with an Enya based monikker (sound and shortmusic clip)

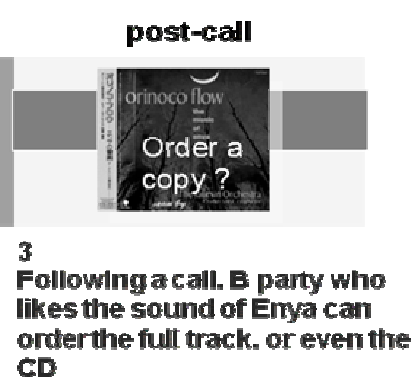

Figure 13. Monikker Network Marketing 

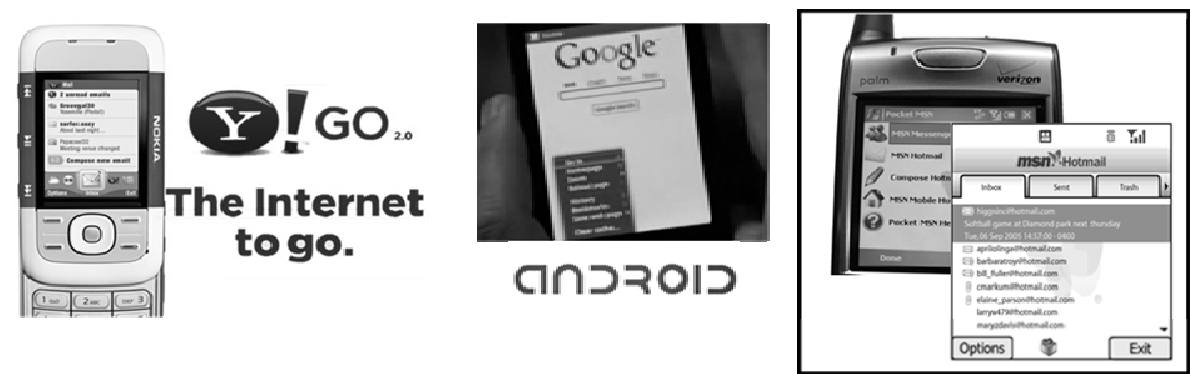

Figure 14 .Yahoo Go advertisement

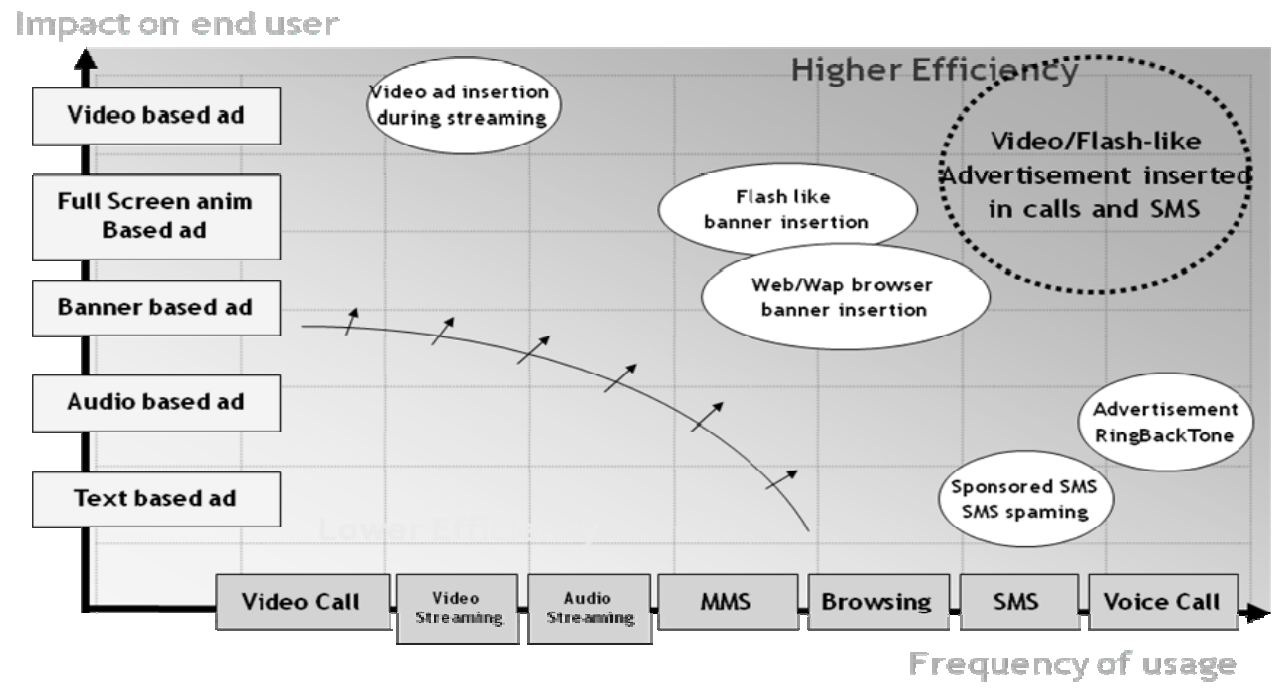

Figure15. Efficiency of the different mobile advertisement options

pre-call

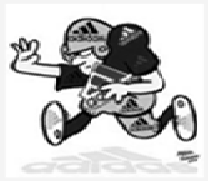

Audio-visual call announcement call

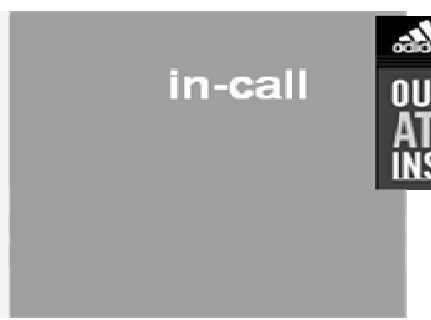

end of call

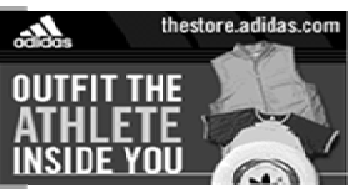

Postcall Advertisement post-call

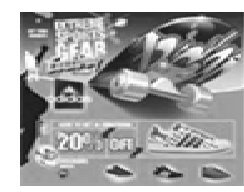

Address Book Update

Figure 16. Call model for advertisement 

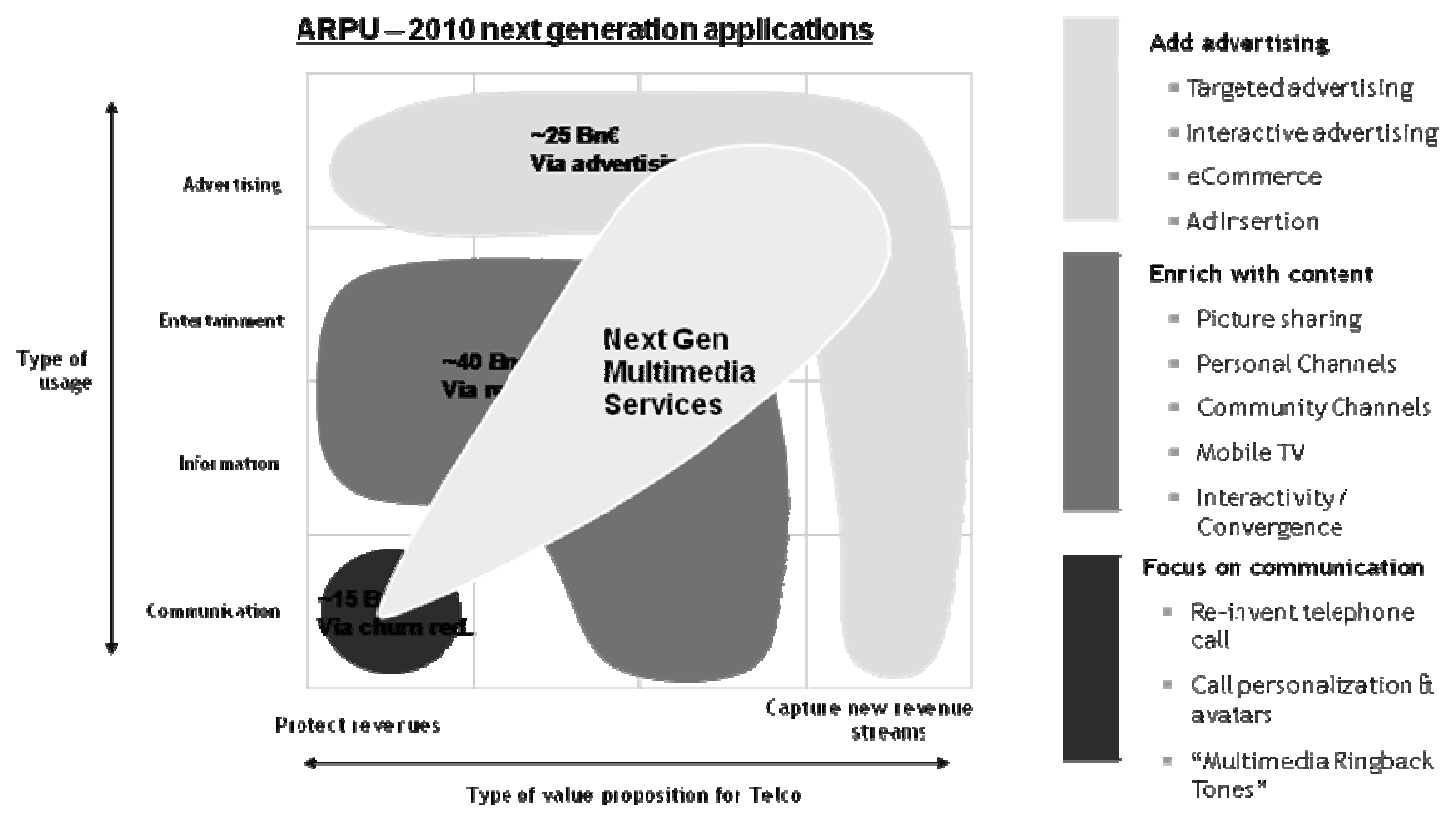

Figure 17. Personalization of Calling Experience - Fits in 1st wave of revenue growth

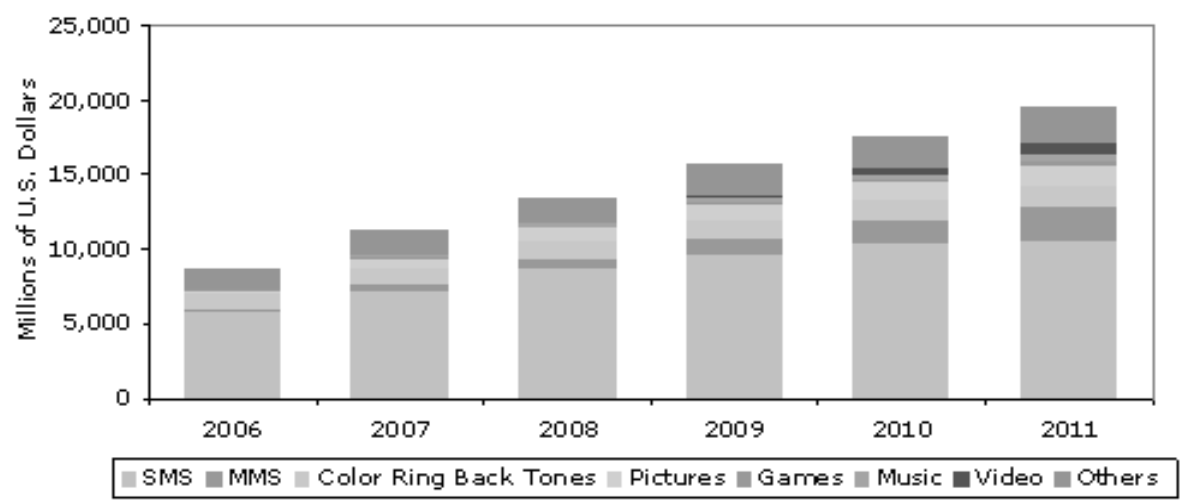

Figure 18. China's $3 \mathrm{G}$ value added service forecast 